\title{
Levamisole Induced Pauci Immune Focal Necrotizing and Crescentic Glomerulonephritis
}

\author{
Randula Ranawaka $^{1} \cdot$ Manoji P. Gamage $^{2} \cdot$ Kalpani Lokuge $^{3} \cdot$ David V. Milford $^{4}$
}

Received: 27 April 2017 / Accepted: 15 December 2017 / Published online: 2 January 2018

(C) Dr. K C Chaudhuri Foundation 2017

To the Editor: Levamisole has been used successfully in the management of nephrotic syndrome (NS) in childhood [1]. Due to its ability to act as a hapten, levamisole may cause increased formation of antibodies to various antigens [2].

Our patient, a 10-y-old girl with frequently relapsing steroid sensitive NS presented with purpuric rash and nodules over lower and upper limbs. She has been on levamisole $(2.5 \mathrm{mg} / \mathrm{kg})$ alternate days for two and half years. The serum creatinine 3 mo before was $56 \mu \mathrm{mol} / \mathrm{l}$. She was pale but there was no organomegaly. She had elevated blood pressure of $134 / 72 \mathrm{mmHg}$.

Her urine albumin/creatinine ratio was $156 \mathrm{mmol} / \mathrm{mg}$. Full blood count (FBC) showed pancytopenia and serum creatinine was $98 \mu \mathrm{mol} / \mathrm{l}$. Anti-neutrophil cytoplasmic antibodies (ANCA) were positive with high titres. Antinuclear antibodies (ANA) and anti-double stranded DNA antibodies (DsDNA) were negative. The complement C3 and $\mathrm{C} 4$ were normal. The bone marrow biopsy was normal. The renal biopsy showed pauci immune focal necrotizing and crescentic glomerulonephritis.

The levamisole was stopped immediately. The patient received methyl prednisolone $600 \mathrm{mg} / \mathrm{m}^{2}$ and was followed up by intravenous cyclophosphamide; then started on daily dose of oral prednisolone $60 \mathrm{mg} / \mathrm{m}^{2}$ for $4 \mathrm{wk}$. All three cell lines showed improvement after two weeks of stopping levamisole.

Randula Ranawaka

rrandula@yahoo.com

1 Department of Pediatrics, Faculty of Medicine, University of Colombo, Colombo, Sri Lanka

2 Lady Ridgeway Hospital for Children, Colombo, Sri Lanka

3 Colombo North Teaching Hospital, Ragama, Sri Lanka

4 Birmingham Children's Hospital, Birmingham, UK
At the three months follow-up, urine albumin/creatinine ratio was normal, renal functions revealed serum creatinine of $62 \mu \mathrm{mol} / \mathrm{L}$ and serum ANCA was negative.

There are several case reports of levamisole induced vasculopathy following use of levamisole-adulterated cocaine in Europe and USA. Study done by McGrath and colleagues described 30 patients with ANCA positivity associated with levamisole contaminated cocaine use; two developed severe acute kidney injury leading to chronic kidney disease [3].

A systemic drug induced syndrome usually affects the skin and the subcutaneous part of the skin, but sometimes also the kidney and the lungs [4]. Early withdrawal of the offending drug usually leads to complete recovery while more advanced disease and late withdrawal of the drug may necessitate use of immunosuppressive therapy. Patients with drug induced vasculitis typically harbour ANCA directed to one or more neutrophil cytoplasm antigens.

Therefore, patients on long term treatment with drugs able to induce vasculitis should be monitored carefully. It seems that serum ANCA can be used as a good marker for this purpose.

Compliance with Ethical Standards

Conflict of Interest None.

\section{References}

1. Eddy A, Symons JM. Nephrotic syndrome in childhood. Lancet. 2003;362:629-39.

2. Macfarlane DG, Bacon PA. Levamisole-induced vasculitis due to circulating immune complexes. Br Med J. 1978;1:407-8.

3. Mc Grath M, Isakova T, Rennke $\mathrm{H}$, et al. Contaminated cocaine and anti-neutrophil cytoplasmic antibody-associated disease. Clin J Am Soc Nephrol. 2011;6:2799-805.

4. Pearson T, Bremmer M, Cohen J, et al. Vaculopathy related to cocaine adultered with levamisole: a review of the literature. Dermatol Online J. 2012;18:1. 